\title{
Toxicity studies of agarwood essential oil in vero cells using electrical impedance sensor
}

\author{
Ahmad Fairuzabadi Mohd Mansor a, Phirdaous Abbas ${ }^{b}$, Taufik Hakim Hamdan a, Yumi Zuhanis \\ Has-Yun Hashim b, Anis Nurashikin Nordin a, ${ }^{*}$
}

a Department of Electrical and Computer Engineering, Kulliyyah of Engineering, IIUM Kuala Lumpur, Malaysia

${ }^{b}$ Department of Biotechnology Engineering, Kulliyyah of Engineering, IIUM Kuala Lumpur, Malaysia

*Corresponding author: anisnn@iium.edu.my

Article history

Received 16 October 2017

Accepted 6 December 2017

\begin{abstract}
Natural products have traditionally been used for medicinal purposes in Asian communities. Toxicity studies typically use animal testing to predict the harmfulness of a particular substance to human health. For this study, in lieu of animal testing, we utilized cell-based biosensors to evaluate the toxicity of natural products. The cell-based biosensors were fabricated on a printed circuit board with copper electrodes and equipped with PDMS cell culture chambers. Two different electrodes (interdigitated and circular) were designed. Vero cells were used to represent normal healthy cells. The cells were first cultured on the biosensors and then inoculated with natural products, Taxol (chemo drug - positive control), and DMSO (negative control). Impedances of these biosensors were afterwards recorded at six-hour intervals for 80 hours to determine the growth of the cells. It was found that as compared to Taxol, natural products have substantially low toxicant values.
\end{abstract}

Keywords: Impedance biosensor, natural product, agarwood, vero cells, AD5933

\section{INTRODUCTION}

This article is an extension of the work presented during the IMEDITEC17 Conference in September 2017. This article provides more comprehensive details on the previous work as the study developed further by comparing the response of the natural product against Vero cells with our previous testing of natural product against breast cancer cell lines, MCF7 (Abbas et al., 2017).

\section{Natural products}

A diverse family of natural products (NPs) have shown to be remarkably useful in many applications such as in biomedicine and agriculture (Demain, 2014; Giddings and Newman, 2013; Katz and Baltz, 2016). Natural products originating from plants have been utilized in various aspects of medicine for thousands of years. Natural products are small molecules found and produced naturally by any organism, which includes primary and secondary metabolites. The practice of employing natural products in medicine had been recorded in history as documentation in relation to the preparation as well as dosage and treatment regiments can be found in old scriptures. Currently, the search for pharmaceutically active compounds from natural sources continues with new natural metabolites being tested for their efficacy as therapeutics (Shankar Subramaniam et al., 2015).

Of particular interest is agarwood, a natural product considered to be one of the finest natural incense and is being used to fulfil cultural, religious, and medicinal purposes. This natural product has profound uses in many cultures including Arabian, Chinese, and Japanese, besides also being associated with religious history, rituals and ceremonies in Buddhism, Christianity, Hinduism, and Islam (Barden et al., 2000). Its ties to diverse cultures have led it to become known with different names such as 'gaharu' in Indonesia and Malaysia, 'jin-koh' in Japan, 'chen hsiang' or 'chen xiang' in China, agar in India, 'chim hyuang' in Korea, 'kritsana noi' in Thailand, and 'oud' in Middle east (Hashim et al., 2016). Fig. 1 shows the Aquilaria spp. tree and products developed for the market. Agarwood formation is due to a self-defence mechanism initiated by the tree to fight off pathogens invading through holes and wounds on the tree surface. Today, agarwood trees are being planted systematically in plantations and the formation of agarwood (resin) is being induced through inoculation of microbial concoctions.

Traditionally, agarwood and its plant materials have been used to treat various conditions and ailments including inflammatory related diseases such as rheumatism, arthritis, body pain, asthma and gout, either via direct oral ingestion or ointment, laxative aid, acting as aphrodisiac and stimulant as well as sedative, analgesic and carminative agents. A review by Hashim (Hashim et al., 2016) collated evidences of the biological effects of agarwood and its associated materials from various works which suggest that agarwood may contain pharmaceutically active compounds that can be further developed into practical and versatile products that can improve quality of life.

More recent studies have concluded that agarwood plants possess various bioactivities such as anti-allergy, anti-cancer, antiinflammatory, anti-ischemic (cardioprotective), antimicrobial, antioxidant, anti-depressant (effects on the central nervous system), as well as hepatoprotective, laxative and mosquitocidal effects (Hashim et al., 2016). One of the earliest scientific works on agarwood was conducted by Gunasekara (Gunasekera et al., 1981) where the alcoholic extract from the stem bark and stem of Aquilaria malaccensis was shown to exhibit mild cardiotonic activity and anti-cancer effects against nasopharyngeal carcinoma in Eagle's medium. In 2009, Feng (Feng et al., 2009) studied the extract obtained from the leaves of Aquilaria sinensis and reported anti-inflammatory, antitumor, analgesic, therapeutic, and prophylactic activity on constipation, intestinal obstruction, and obesity; therapeutic effects on haemorrhage and cerebral ischemia; and causes reduction of blood glucose. Another 
study found that when wounded, agarwood trees initiate a defence system that produces secondary metabolites that were proven to have health benefits, which includes terpenes, phenolics and alkaloids (Mohamed et al., 2012). Researchers have also found that agarwood possess potent antioxidant, anti-inflammatory and anticancer properties against colorectal carcinoma cells (HCT 116) and pancreatic cancer cells (MIA PaCa-2), which were mediated via apoptotic mechanism (Dahham et al., 2015a; Dahham et al., 2015b).

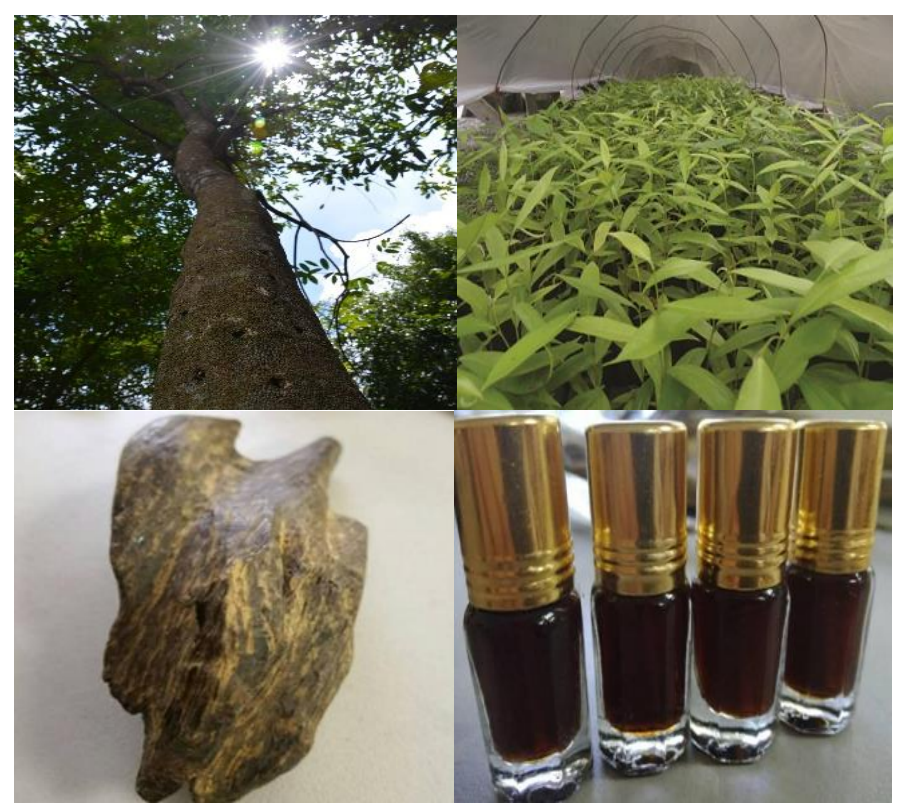

Fig. 1 Images of agarwood tree (Aquilaria malaccensis) and seedlings (Aquilaria subintegra) that are usually found in Malaysia and Thailand, respectively. The dark wood block is hardened agarwood resin and agarwood oil available in the market (photo: P. Abbas 2016, Kajang, Selangor, Malaysia).

\section{Electrical impedance sensing}

Electrical cell sensing method is a well-known technique for realtime monitoring of cellular conditions that is non-invasive, simple and based on impedance measurements of cells. It is a cost-effective and rapid technique that can act as an alternative to animal testing and live cell imaging technique (Campbell et al., 2007; Tran et al., 2016). Realtime monitoring of cells is significant to study the response of cells towards external treatment or drug introduction. Numerous research have applied this concept; to note a few examples, studies of toxicity in water (Tan and Schirmer, 2017), drug discovery (Lundstrom, 2017), wound healing (Cui et al., 2017) and cell growth and toxicity (AnhNguyen et al., 2016; Mansor et al., 2015a)

Theoretically, in order to study cell adhesion using electrical impedance sensing, a low frequency signal will be applied to the working electrodes of the biosensor. Initially, under controlled environment, the current generated by the AC signal will easily flow from the working electrode to the counter electrode in a two-electrode system. Cells cultured in the system will adhere and proliferate on the surface of the electrodes, causing restriction of current flows from the electrodes to the surrounding media. In a confluent cell layer, current must travel through the intercellular space of the cell-cell and also the tight gap of the cell-electrode pairs to reach surrounding media. The more adherent and closely packed the cells are with each other and with the electrode, the lesser the amount of current that can travel out, thus increasing the overall impedance of the system. (Heileman et al., 2013).

In view of the potential benefits of agarwood products, this study aims to: i) study the cytotoxic effects of agarwood on Vero cells (kidney epithelial cells); ii) compare the effectiveness of using a biosensor as an alternative to T-flask testing for cytotoxicity testing. Vero cells were employed as they exhibited the same sensitivity as healthy human cells.
This method was shown to be simpler but as reliable as the rabbit skin test (Miyamura et al., 1974). Vero cells were cultured and maintained inside T-Flask until it reached confluency before being seeded into the biosensor. All drugs were introduced 24 hours following the cell seeding procedures.

In this study, we present a printed circuit board impedance biosensor with copper electrodes based on our previous work (Mansor et al., 2015b) for toxicity studies of natural products on normal healthy cells (Vero cells). For comparison, the Vero cells were also exposed to Taxol (chemo drug - positive control) and DMSO (negative control). The impedance biosensor operates on the basis that healthy cells adhere to the sensor's electrodes impeding current flow, resulting in high impedance. A high impedance also correlates to a high cell index, indicating that more cells adhere on the electrode surface. Conversely, low impedances reflect that less cells are attached to the electrodes, and this occurs when the cells are dead. Dead and unhealthy cells are usually non-adherent and slowly detach themselves from the electrodes leading to a decrement in cell index.

\section{MATERIALS AND METHOD}

\section{Cell cultures}

Vero cells (ATCC® CCL-81 ${ }^{\mathrm{TM}}$ ) (ATCC, Manassas, VA, USA), a type of normal cell line, was grown and maintained to confluence in Dulbecco's Modified Eagle Medium, DMEM (Gibco, Paisley, UK) supplemented with $10 \%$ heat inactivated fetal bovine serum (FBS; Gibco). The Vero cells were incubated under standard cell culture environment in $\mathrm{CO}_{2}$ incubator at $37^{\circ} \mathrm{C}$ with atmosphere containing $5 \%$ carbon dioxide, $\mathrm{CO}_{2}$. Once confluent, the cells were detached from the culture flask using accutase and were then resuspended in fresh media. The suspended cells were counted and the media of density $1 \times 10^{5}$ cells $/ \mathrm{ml}$ in $100 \mu \mathrm{L}$ was seeded on each biosensor.

\section{Gelatin preparation and cell adhesion coating}

Gelatin coating is necessary for long term (7-14 days) maintenance of cells. Gelatin coating was performed before seeding feeder cells into the chamber. For preparation of a $1 \%$ gelatin, 0.1 gram of gelatin was taken out of the container and put into $100 \mathrm{ml}$ of double distilled water. Next, it was sterilized in an autoclave sterilizer at $121^{\circ} \mathrm{C}$ for about 15 minutes. In a biosafety cabinet, $0.1 \%$ gelatin was added to each chamber to coat it. After gelatin was poured into each chamber, it was incubated for a minimum of 30 minutes at a temperature of $37^{\circ} \mathrm{C}$ and the excess was discarded. Each of the chambers have to be dried for at least two hours before cell seeding. Ready chambers were sealed with parafilm for storing purposes.

\section{Agarwood and toxicity test}

In this study, a total of three treatments were sampled at $10 \mu \mathrm{l}$. Natural product, i.e. the agarwood branch ethanolic crude extract, was seeded at a final working concentration of $\mathrm{IC}_{50} 6 \mu \mathrm{g} / \mathrm{ml}$; Taxol, a commercial cancer drug, was seeded at a final working concentration of $\mathrm{IC}_{50} 2.3 \mu \mathrm{g} / \mathrm{ml}$; and DMSO, a negative control was seeded at a concentration of $10 \%(\mathrm{v} / \mathrm{v})$. All $\mathrm{IC}_{50}$ values were based on the response of MCF-7 breast cancer cells from different studies. All treatments were introduced 24 hours subsequent to cell seeding. The response of the cells to the drugs was plotted as cell index number in the next section.

\section{Sensor fabrication}

Copper electrodes were designed and fabricated on FR4 board using standard PCB fabrication processes i.e. UV exposure, development, etching and finishing, as shown in Fig 2. In this study, two different types of electrodes were modelled-interdigitated electrode and circular electrode - as shown in Fig. 3 with dimensions as given in Table 1. Each board contains eight sets of identical and parallel sensor designs that were used for the experiments. Sensors were kept in a dry place to avoid oxidation, and were cleaned with ethanol and PBS. All sensors were exposed to UV light for a night for sterilization process prior to ECM coating and cell seeding. 
Mansor et al. / Malaysian Journal of Fundamental and Applied Sciences

Special Issue on Medical Device and Technology (2017) 540-545

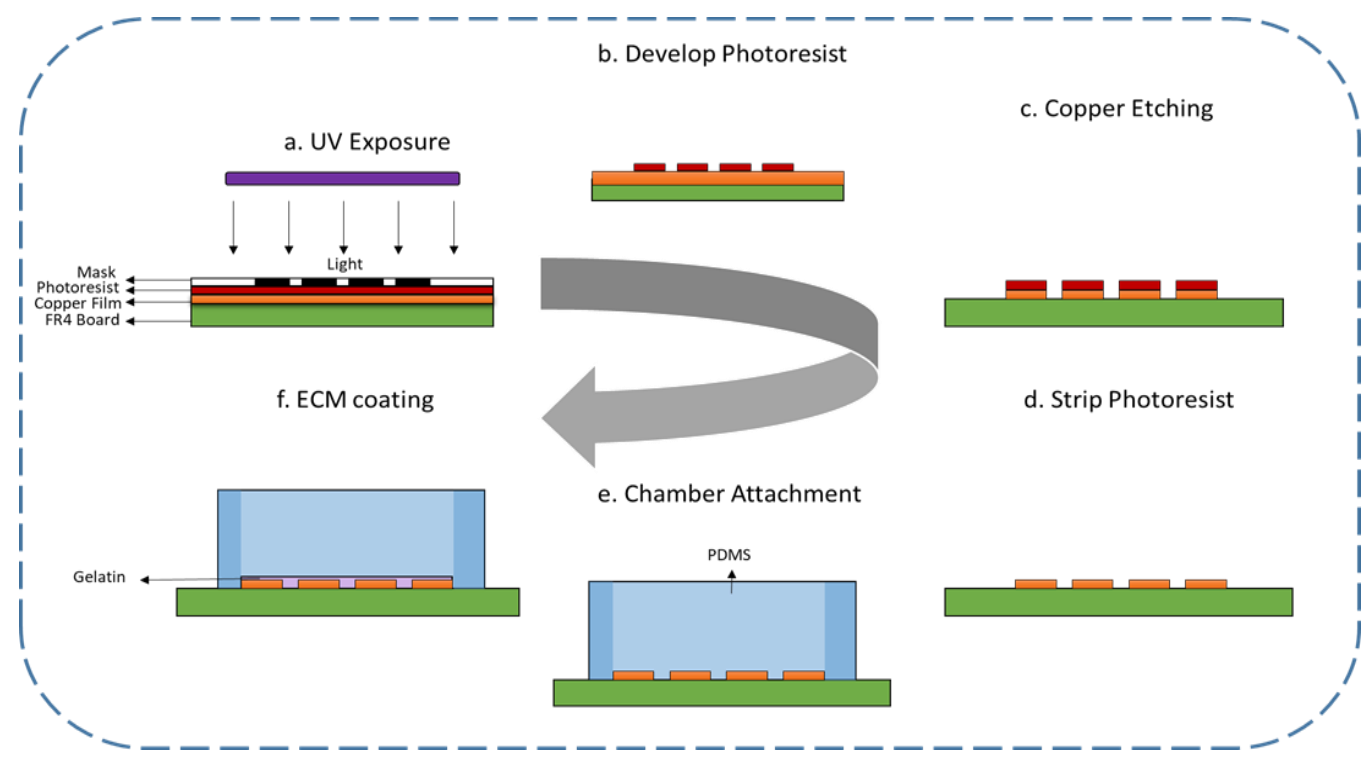

Fig. 2 Process flow for fabrication of the impedance biosensor; (a) Positive PCB board was exposed to UV light for 180 seconds to polymerize the photoresist; (b) Unpolymerized photoresist was developed in sodium hydroxide for a few minutes; (c) Unwanted copper was etched in ferric chloride solution, leaving only the traces of the design; (d) Photoresist layer was removed via stripping process; (e) Culture well made of PDMS was attached on the sensor for cell culture purposes; (f) Gelatin was coated on the electrodes to improve cellular adhesion on the electrodes

Table 1 Size and dimension parameters of the electrode.

\begin{tabular}{ccc}
\hline $\begin{array}{c}\text { Electrode } \\
\text { Design }\end{array}$ & Parameter & $\begin{array}{c}\text { Dimension } \\
(\boldsymbol{\mu m})\end{array}$ \\
\hline Interdigitated & $\mathrm{s}$ & 350 \\
Electrodes & $\mathrm{w}$ & 500 \\
& $\mathrm{I}$ & 6100 \\
Circular & $\mathrm{d}$ & 5000 \\
Electrodes & $\mathrm{s}$ & 550 \\
& $\mathrm{t}$ & 350 \\
\hline
\end{tabular}

\section{PDMS Fabrication}

Sylgard 184 Silicone Elastome Kit was used when making Polydimethylsiloxane (PDMS). The elastomer and curing agent were weighed and mixed at a standard ratio of 10:1 and left overnight to solidify in a closed container. Once hardened, the PDMS was cut to fit the electrode size, punctured to make wells on top of the electrode, glued onto the sensor using another form of liquid PDMS and left overnight to dry and harden.

\section{AD5933 Impedance Converter Analyzer}

The impedance network converter integrated circuit AD5933 is the core of the measurement system. Based on its basic configuration, AD5933 can measure impedance from $1 \mathrm{k} \Omega$ to $10 \mathrm{M} \Omega$ in the frequency range of 1 to $100 \mathrm{kHz}$ (Yusoff, 2016). The Analogue Front End (AFE) can measure impedance at low frequencies through the instrumentation amplifiers, general application op-amp circuits and voltage references using the provided software. There are four steps in measuring the impedance with the evaluation board, which include system setup, system calibration, impedance measurement and data acquisition. The data transmission of the impedance can be done through the $\mathrm{I}^{2} \mathrm{C}$ port connected to a computer through USB connection.

\section{T-Flask Protocol}

As a point of reference for the biosensor testing, the conventional method of cell culture using T-flasks were also performed and microscopic cell counting using hemocytometer was done on the cells inoculated with the natural products. Initially, a total of 13 flasks were prepared and cell-counting was completed every six hours corresponding to the impedance measurements. The media of density $1 \times 10^{5}$ cells $/ \mathrm{ml}$ in $5 \mathrm{ml}$ was seeded inside each flask. The graphical scheme of the experimental protocol is shown in Fig. 4.

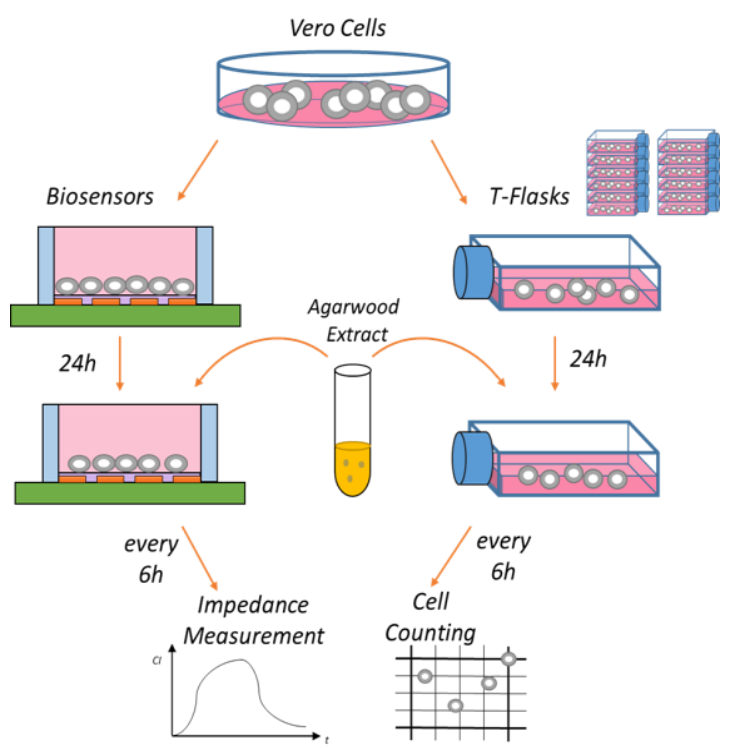

Fig. 3 Geometry of the circular and interdigitated electrodes and the fabricated sensors attached together with PDMS chamber and wire soldered for impedance measurement. Inset- Design of the PCB mask for PCB fabrication.

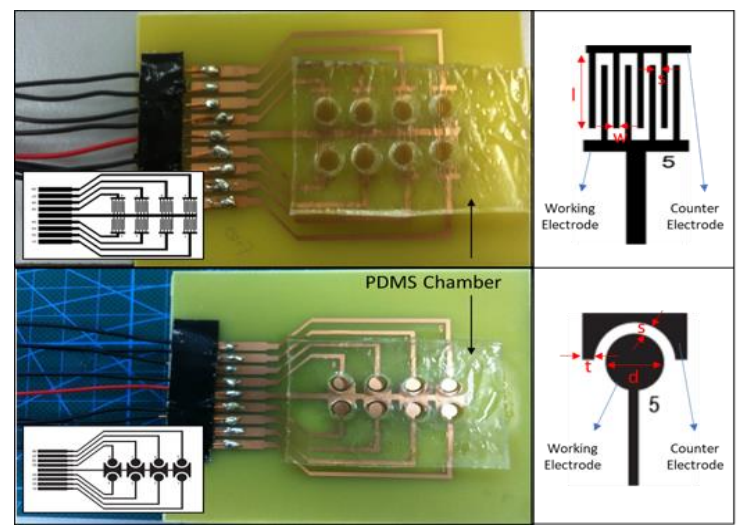

Fig. 4: Experimental protocol in comparing biosensing and cell counting techniques 


\section{Experimental Setup for Biosensor Test}

In the experiment, sensors were retained inside the incubator at all times except during impedance measurement. Every six hours, the sensors were taken out for data acquisition using AD5933 evaluation board, which was connected to a laptop. Cell impedance and phase at specific times were measured using an AC frequency of $180 \mathrm{~Hz}$. The impedance and phase were converted into resistance and cell index (CI). Fig. 5 shows the setup of the experiment.
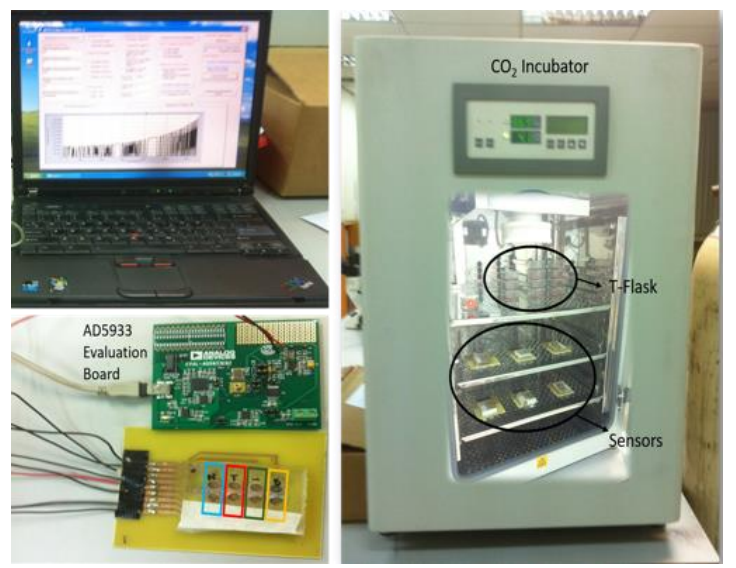

Fig. 5 Right-Sensors and T-flask positioned inside the incubator. LeftImpedance and phase measurements were taken using AD5933 evaluation board and laptop. Four sets of double experiments were conducted on a single board: cell+natural product (blue box), cell+taxol (red box), cell+DMSO (green box) and control cell without drugs (yellow box).

\section{RESULTS AND DISCUSSION}

\section{Cell Index $(\mathrm{Cl})$ representation of cell}

Measurement using AD5933 evaluation board gives the magnitude of impedance and phase of the biosensors. Since CI is a much more accurate representation of cellular behaviour (Boyd et al., 2008) on the surface of electrodes, the impedance and phase were converted into CI number. CI is directly related to cell viability. Higher CI number indicates that more cells are adhering on the electrode surface. The CI for cellular growth can be expressed based on Eq. (1)

$$
C I=\max _{i=1, . . N}\left[\frac{R_{\text {cell }}\left(f_{i}\right)}{R_{b}\left(f_{i}\right)}-1\right]
$$

where $R_{b}$ represents the frequency-dependent resistance of control measurement (without cells) and $R_{\text {cell }}$ indicates the frequencydependent resistance of the cells and electrodes. Measured resistances, $\mathrm{R}$ were extracted from $\mathrm{Z}$ and $\theta$ using Eq. (2) and Eq. (3):

$$
\begin{gathered}
|Z|=\sqrt{R^{2}+X^{2}} \\
\theta=\tan ^{-1}\left(\frac{X}{R}\right)
\end{gathered}
$$

\section{Biosensor and T-Flask comparison}

Fig. 6 shows the comparison of monitoring NP exposure on Vero cells using two techniques, i.e. conventional method of trypan blue exclusion and impedance biosensor. A similar graph trend can be seen from both methods where the highest number of cell count was shown at time of 60 hours, correlating to the highest measured CI. Fluctuation of $\mathrm{CI}$ in several measurements were due to limitation of growth caused by limited surface area. For this case, the T-flask offers larger surface area for adhesion compared to biosensors, where dead cells need to be detached before making space for the next adhesion process. These results indicated that the biosensor can be used to predict the response of cells towards drugs exposure. The IDT electrode design showed higher CI values ranging from 0.08 to $0.5 \mathrm{CI}$ compared to that of circular electrode ranging only from 0.01 to $0.3 \mathrm{CI}$, suggesting a higher accuracy representation of cellular activities thus concluded as having better sensitivity between both designs.

This result is apparently in agreement with the theoretical concept discussed in a study conducted by Varshney in 2009 (Varshney and Li, 2009). Their article suggested that IDT electrodes show better sensitivities compared to other coplanar electrode designs. The main advantage of IDT electrodes is that they provide uniform and confined electric field distribution between the electrodes, allowing the IDT to detect smaller morphological changes of cells.

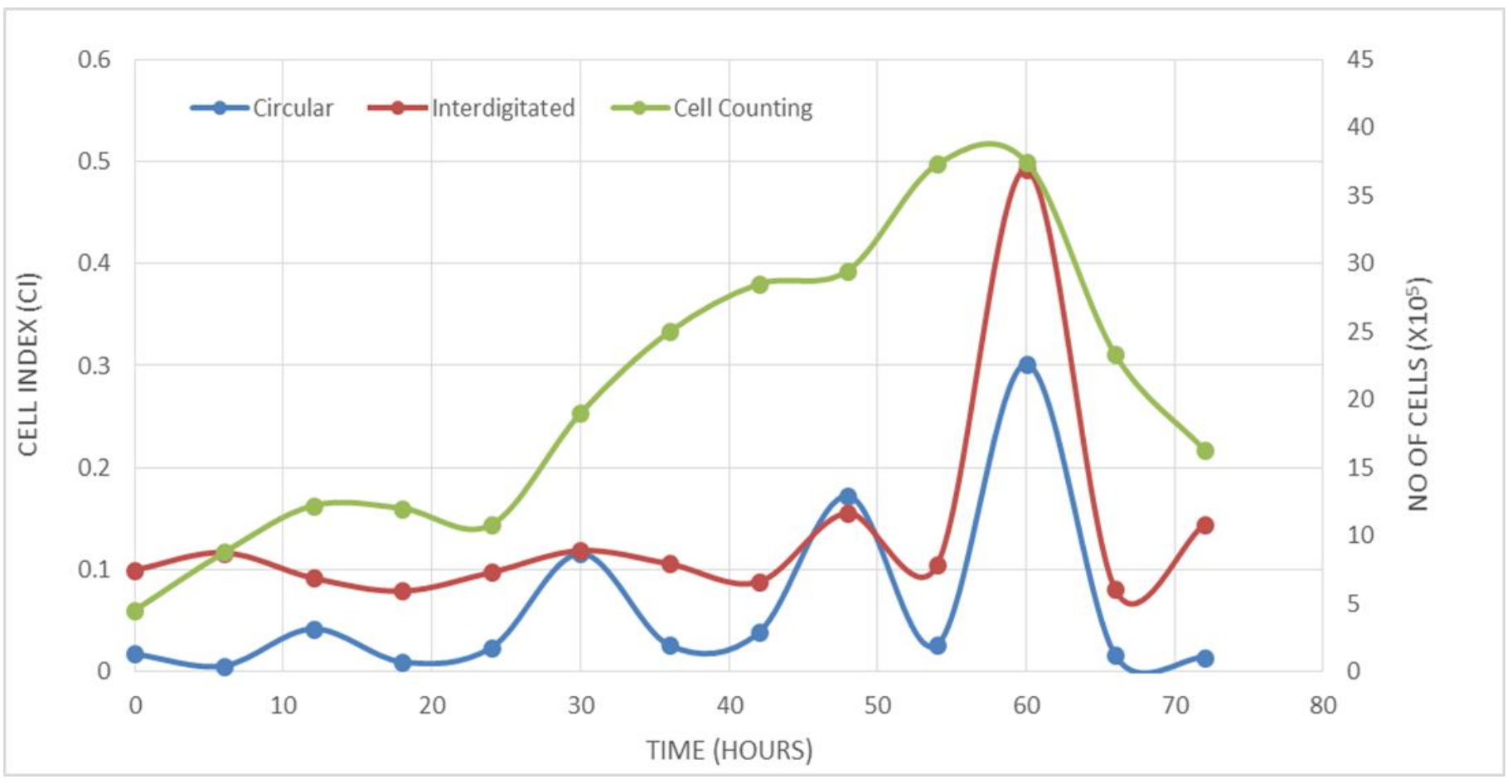

Fig. 6 Comparison of cell counting using T-Flask method and cell indexing using biosensors 


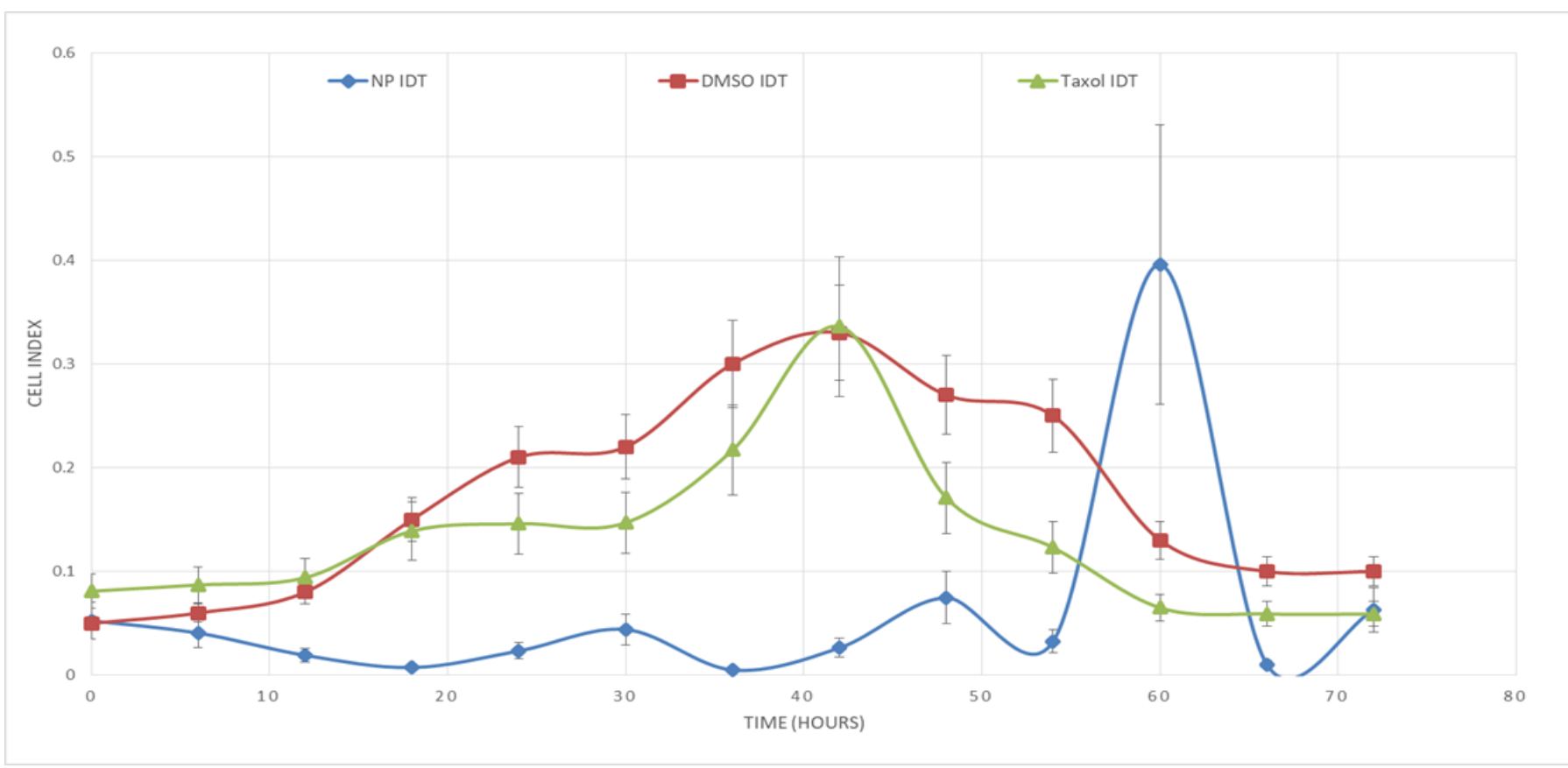

Fig. 7 Cytotoxicity of NP, Taxol and DMSO on vero cells using IDT electrode sensor.

\section{Cytotoxicity evaluation of NP, Taxol and DMSO using impedance biosensor}

Cytotoxic evaluation of NP, Taxol, and DMSO were performed on IDT electrode-design sensor as it has better sensitivities compared to the circular design. From the results in Fig. 7, both Taxol and DMSO showed similar trendlines. Taxol did not show major toxicity effects towards Vero cells at the concentration tested, which was our target for positive control. However, the results did indicate a slightly lower CI when exposed to Taxol compared to DMSO, which tells us that there were still less viable cells on the electrodes for Taxol over DMSO.

Meanwhile, NP showed slower growth between 0-60 hours whereby the maximum CI was achieved at 60 hours. This indicates that NP suppresses the growth rate of Vero cells (causing longer lag phase). There is a possibility that NP produces similar effects as Taxol, which targets the microtubule of the cells and prevents them from producing the protein needed for cell attachment. However, this effect is not necrotic, as the cells can still adhere and proliferate on the electrode surface, producing a higher CI number compared to the peak of Taxol and DMSO curves. Earlier findings imply that NP has cytostatic effects on Vero cells. Based on these studies, it can be concluded that the impedance-based biosensor shows great potential to be used as a tool to study the toxicity of natural products. Nevertheless, more work needs to be done to impart more data on cytotoxicity testing of different drugs and on different adherent cells to demonstrate the compatibility of the biosensor to various drug studies.

\section{Cytotoxicity comparison of NP on Vero and MCF-7}

A more recent study was conducted in order to investigate the effects of agarwood plant material against MCF-7 breast cancer cells (Abbas et al., 2017). The study concluded that the uninfected agarwood branch ethanolic extract exhibited potent cytotoxic effect against MCF7 cells. The experiment managed to show cell density reduction as well as morphology change due to the exposure to agarwood branch ethanolic extract (ABEE) of which the $\mathrm{IC}_{50}$ value was estimated to be at $8 \mu \mathrm{g} / \mathrm{ml}$ and $6 \mu \mathrm{g} / \mathrm{ml}$ for optimized extract. Meanwhile, Taxol, a commercial drug for cancer, was also tested in the experiment as positive control whereby the estimated IC $_{50}$ value was $2.3 \mu \mathrm{g} / \mathrm{ml}$. Fig. 8 shows the population density change when MCF-7 was treated with ABEE. The cytokinetic study showed reduction of cell generation and specific growth rate in ABEE-treated cells as compared to control. Meanwhile, in a separate experiment by using assay techniques, ABEE was also observed to cause reduction in Vero cells (normal green monkey kidney), however the effects were seen only at higher concentrations of ABEE $(64 \mu \mathrm{g} / \mathrm{ml})$. Noticably, contradicting results may be seen from the biosensors and cell counting techniques in reference to different experimental works. The same reduction response of the ABEE on Vero cells were attained in both techniques but occurred at different levels of concentration, suggesting that the experimental design of the biosensor should be refined. This includes optimizing the ratio of medium volume and cell seeding density towards the growth surface area; this is a parameter to be concerned about, such that the outcome between these two techniques can be correlated.
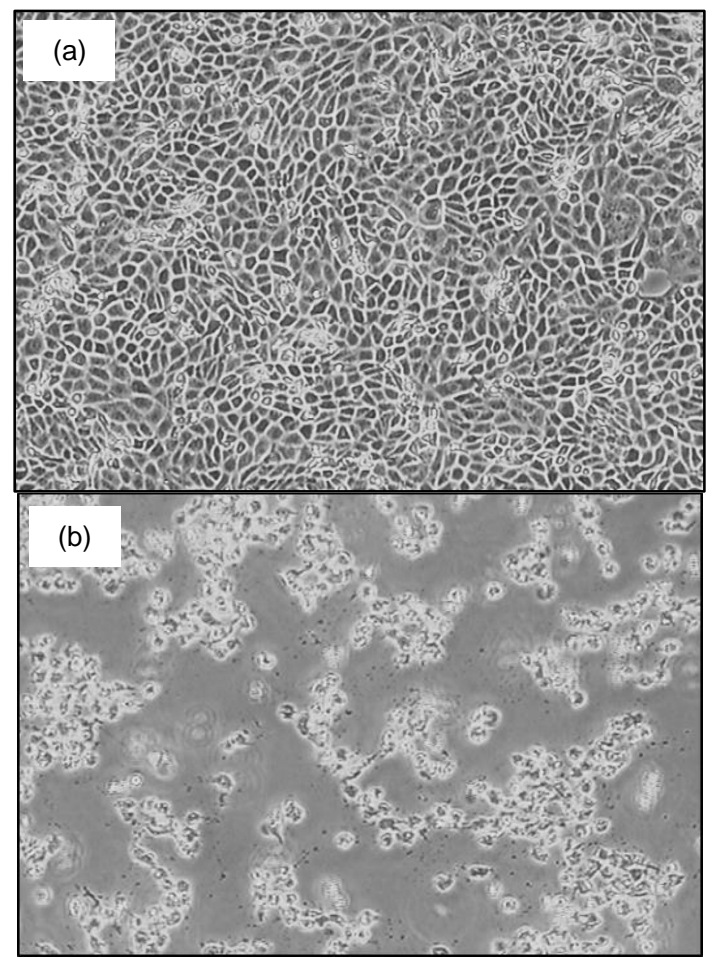

Fig. 8 Images of MCF-7 population density a) control group and b) ABEE group after 48 hours of incubation. Density of cells in ABEE treated group was less and morphology dissimilarity can also be detected when compared with the control group (treated with $10 \%$ dimtehylsulfoxide) (Abbas et al., 2017). 


\section{CONCLUSION}

In this study, PCB board sensors had been fabricated based on two designs, the IDT and circular electrode. IDT was observed to have better sensitivity based on a higher CI number compared to the latter, hence a more accurate representation of cellular behaviour. The impedance-based biosensor has been shown to have great potential as a real-time and cost-effective tool to study the toxicity of natural products.

As with natural products, ABEE exhibits reduction on both MCF7 and Vero cells indicating that the same set of response can indeed occur but at different concentrations of IC50. ABEE can safely be regarded as less toxic than Taxol and DMSO. However, optimizations on the experimental framework of the biosensor should be done in order to have a correlated study between these two approaches.

\section{ACKNOWLEDGEMENT}

This work was supported by the Ministry of Science, Technology and Innovation EScience grant (SF16-004-0073). The researchers wish to thank Assoc. Prof. Dr. Raha Ahmad Raus, Department of Biotechnology Engineering, IIUM for providing the Vero cells.

\section{REFERENCES}

Abbas, P., Hashim, Y. Z. H.-Y., and Amid, A. (2017). Cytokinetic study of uninfected agarwood branch ethanolic extract on breast cancer cells. AsiaPacific Journal of Molecular Biology and Biotechnology, 25, (1-7).

Anh-Nguyen, T., Tiberius, B., Pliquett, U., and Urban, G. A. (2016). An impedance biosensor for monitoring cancer cell attachment, spreading and drug-induced apoptosis. Sensors and Actuators A: Physical, 241, 231-237.

Barden, A., Anak, N. A., Mulliken, T., and Song, M. (2000). Heart of the matter: Agarwood use and trade and CITES implementation for Aquilaria malaccensis. TRAFFIC International, Cambridge, UK.

Boyd, J. M., Huang, L., Xie, L., Moe, B., Gabos, S., and Li, X.-F. (2008). A cellmicroelectronic sensing technique for profiling cytotoxicity of chemicals. Analytica chimica acta, 615(1), 80-87.

Campbell, C. E., Laane, M. M., Haugarvoll, E., and Giaever, I. (2007). Monitoring viral-induced cell death using electric cell-substrate impedance sensing. Biosensors and Bioelectronics, 23(4), 536-542.

Cui, Y., An, Y., Jin, T., Zhang, F., and He, P. (2017). Real-time monitoring of skin wound healing on nano-grooves topography using electric cellsubstrate impedance sensing (ECIS). Sensors and Actuators B: Chemical, 250, 461-468.

Dahham, S. S., Tabana, Y. M., Ahamed, M. B. K., and Majid, A. M. A. (2015a). In vivo anti-inflammatory activity of $\beta$-caryophyllene, evaluated by molecular imaging. Molecules \& Medicinal Chemistry, 1 .

Dahham, S. S., Tabana, Y. M., Iqbal, M. A., Ahamed, M. B., Ezzat, M. O., Majid, A. S., et al. (2015b). The anticancer, antioxidant and antimicrobial properties of the sesquiterpene $\beta$-caryophyllene from the essential oil of Aquilaria crassna. Molecules, 20(7), 11808-11829.
Demain, A. L. (2014). Importance of microbial natural products and the need to revitalize their discovery. Journal of Industrial Microbiology \& Biotechnology, 41(2), 185-201.

Feng, J., Yang, X.-W., and Liu, T.-H. (2009). RP-LC Quantification and Pharmacokinetic Study of Iriflophenone 2-O- $\alpha$-Rhamnopyranoside in Rat Plasma. Chromatographia, 70(7-8), 1227.

Giddings, L.-A., and Newman, D. J. (2013). Microbial natural products: molecular blueprints for antitumor drugs. Journal of Industrial Microbiology \& Biotechnology, 40(11), 1181-1210.

Gunasekera, S. P., Kinghorn, A. D., Cordell, G. A., and Farnsworth, N. R. (1981). Plant anticancer agents. XIX. Constituents of Aquilaria malaccensis. Journal of Natural Products, 44(5), 569-572.

Hashim, Y. Z. H.-Y., Kerr, P. G., Abbas, P., and Salleh, H. M. (2016). Aquilaria spp.(agarwood) as source of health beneficial compounds: A review of traditional use, phytochemistry and pharmacology. Journal of Ethnopharmacology, 189, 331-360.

Heileman, K., Daoud, J., and Tabrizian, M. (2013). Dielectric spectroscopy as a viable biosensing tool for cell and tissue characterization and analysis. Biosensors and Bioelectronics, 49, 348-359.

Katz, L., and Baltz, R. H. (2016). Natural product discovery: past, present, and future. Journal of Industrial Microbiology \& Biotechnology, 43(2-3), 155 176.

Lundstrom, K. (2017). Cell-impedance-based label-free technology for the identification of new drugs. Expert Opinion on Drug Discovery, 12(4), 335-343.

Mansor, A., Ibrahim, I., Voiculescu, I., and Nordin, A. (2015a). Screen printed impedance biosensor for cytotoxicity studies of lung carcinoma cells. Paper presented at the International Conference for Innovation in Biomedical Engineering and Life Sciences, 122-126.

Mansor, A. F. M., Nordin, A. N., and Ibrahim, I. (2015b). Cytotoxicity studies of lung cancer cells using impedance biosensor. Paper presented at the Smart Sensors and Application (ICSSA), 2015 International Conference on, 1-6.

Miyamura, K., Nishio, S., Ito, A., Murata, R., and Kono, R. (1974). Micro cell culture method for determination of diphtheria toxin and antitoxin titres using VERO cells: I. Studies on factors affecting the toxin and antitoxin titration. Journal of biological standardization, 2(3), 189IN1193-192201.

Mohamed, R., Tan, H. Y., and Siah, C. H. (2012). A real-time PCR method for the detection of trnL-trnF sequence in agarwood and products from Aquilaria (Thymelaeaceae). Conservation Genetics Resources, 4(3), 803806.

Shankar Subramaniam, R. R., Palanisamy, A., and Sivasubramanian, A. (2015). Development and extraction optimization of baicalein and pinostrobin from Scutellaria violacea through response surface methodology. Pharmacognosy Magazine, 11(Suppl 1), S127.

Tan, L., and Schirmer, K. (2017). Cell culture-based biosensing techniques for detecting toxicity in water. Current Opinion in Biotechnology, 45, 59-68.

Tran, T. B., Baek, C., and Min, J. (2016). Electric Cell-Substrate Impedance Sensing (ECIS) with Microelectrode Arrays for Investigation of Cancer Cell-Fibroblasts Interaction. PloS One, 11(4), e0153813.

Varshney, M., and Li, Y. (2009). Interdigitated array microelectrodes based impedance biosensors for detection of bacterial cells. Biosensors and Bioelectronics, 24(10), 2951-2960.

Yusoff, M. A. M. (2016). Development of an AD5933-based Impedance Meter Prototype for Impedimetric Sensor Applications. Procedia Chemistry, 20, 56-59. 